\title{
A RELAÇÃO ENTRE INCIDÊNCIA POĹ́TICA E MOBILIZAÇÃO DE RECURSOS NA AGROECOLOGIA
}

\author{
The Relationship Between Political Incidence and Resource Mobilization in Agroecology \\ La Relación entre la Incidencia Política y la Movilización de Recursos en la Agroecología
}

\section{RESUMO}

0 trabalho apresenta uma análise sobre a relação entre incidência política e mobilização de recursos para a causa da agroecologia. 0 foco é a trajetória da organização não governamental Centro de Estudos e Promoção da Agricultura de Grupo (Cepagro), considerando em particular suas relações. São focalizados dois exemplos de sua atuação, articulada a organizações, movimentos e redes, nas temáticas de gestão de resíduos orgânicos e de diversificação em áreas cultivadas com tabaco, no período de 2006 a 2018 . A pesquisa, de caráter descritivo-analítico, baseia-se em dados coletados por meio de entrevistas semiestruturadas, documentos e observação participante natural e não sistemática. A partir da Teoria do Processo Político, as categorias de análise mobilizadas foram oportunidades políticas, repertórios de ação e redes sociais, complementadas no decorrer da pesquisa. A mobilização de recursos foi abordada como processo de fortalecimento organizacional, fundamentado na construção de uma base social de apoio técnico, político e monetário. Concluiu-se que, na relação entre a organização e o Estado, predomina uma postura de colaboração em torno das temáticas tratadas e da causa defendida. As ações de incidência política são realizadas com grupos de base, outras organizações e sociedade civil em geral. Ainda que o Estado crie as oportunidades políticas, as ações de incidência política e mobilização social executadas pelo Cepagro as influenciam. 0 processo de mobilização de recursos, monetários e não monetários, vai além daquela para a própria organização. Com efeito, trata-se de uma mobilização para a causa defendida.

Palavras-chave: agroecologia, incidência política, mobilização de recursos, movimento social, Cepagro.

\section{Rafael Beghini Ruas ${ }^{1}$}

rrrbeghini@gmail.com

ORCID: https://orcid.org/0000-0002-0278-0747

\section{Paula Chies Schommer ${ }^{2}$}

paulacs3@gmail.com

ORCID: https://orcid.org/0000-0001-9919-0809

1 Cepagro e Universidade do Estado de Santa Catarina, Udesc

2 Universidade do Estado de Santa Catarina, Udesc

Submetido 02-09-2019. Aprovado 02-03-2020

Avaliado pelo processo de double blind review

DOI: http://dx.doi.org/10.12660/cgpc.v24n79.78760 
Rafael Beghini Ruas - Paula Chies Schommer

\section{ABSTRACT}

This paper presents an analysis of the relationship between political incidence and resource mobilization in agroecology. Its focus is the trajectory of the non-governmental organization Center for Studies and Promotion of Group Agriculture (CEPAGRO), particularly its relationships. The study explores two examples of its work, articulated with organizations, movements, and networks, on the subjects of organic waste management and diversification in areas cultivated with tobacco, from 2006 to 2018. The research has a descriptive and analytical approach and is based on data collected through semistructured interviews, documents and natural and non-systematic participant observation. Based on the Political Process Theory, the initial categories for analysis were political opportunities, repertoires of action and social networks, complemented during the research. Resource mobilization was considered as a process of organizational strengthening, supported on a social base with a technical, political and monetary character. Among the conclusions, there is the predominance of a collaborative approach in the organization-state relationship, on the subjects and the cause of agroecology: Political advocacy actions are carried out with grassroots groups, other organizations, and civil society. Although the State creates political opportunities, the political advocacy and social mobilization actions carried out by CEPAGRO influence them. The process of mobilizing resources, both monetary and nonmonetary, goes beyond mobilization for the organization itself and becomes mobilization for the cause being advocated.

Keywords: agroecology, political incidence, resource mobilization, social movement, CEPAGRO.

\section{RESUMEN}

El articulo presenta un análisis sobre la relación entre la incidencia política y la movilización de recursos en la causa de la agroecología. El enfoque es la trayectoria de la organización no gubernamental Centro de Estudios y Promoción del Grupo Agrícola (Cepagro), en particular sus relaciones. Dos ejemplos de las acciones articuladas de diversas organizaciones, movimientos y redes se centran en la gestión de residuos orgánicos y la diversificación en áreas cultivadas con tabaco, de 2006 a 2018. La investigación es descriptiva-analítica, basada en datos recopilados a través de entrevistas semiestructuradas, documentos y observación participante natural y no sistemática. Las categorías de an álisis iniciales, desde la teoría del proceso político, fueron oportunidades políticas, repertorios de acción y redes sociales, y se complementaron durante la investigación. La movilización de recursos fue abordada como un proceso de fortalecimiento organizacional, basado en la construcción de una base social de carácter técnico, político y monetario. Se concluyó que la relación de Cepagro con el Estado prevalece en una actitud colaborativa y constructiva a favor de los temas y la causa defendida por la organización. Las acciones de promoción política se llevan a cabo con grupos de base, otras organizaciones y la sociedad civil en general. Aunque el estado crea las oportunidades politicas, las acciones de promoción política y movilización social llevadas a cabo por Cepagro les influyen. El proceso de movilización de recurșos, monetarios y no monetarios, va mas allá de la movilización para la organización misma y se convierte en movilización para la causa defendida.

Palabras clave: agroecología, incidencia política, movilización de recursos, movimiento social, Cepagro.

\section{INTRODUÇÃO}

\section{A agroecologia constitui-se como campo} científico e sociopolítico no Brasil a partir dos anos 1970, com a emergência da agricultura alternativa, marcada pela contestação ao modelo tecnológico da chamada Revolução Verde, à degradação ambiental e à exclusão social. A partir dos anos 1980, gradualmente se constitui como movimento social, associado a um conjunto de práticas agrícolas. Na década de 1990, o debate ex- pande-se na sociedade. A partir de 2003, a temática é fortalecida no Brasil por meio de políticas públicas, a exemplo de legislação nacional para a produção orgânica, resultado da mobilização de redes e organizações. Embora legitimada pelo movimento social, por diferentes políticas públicas e redes científicas e técnicas, a agroecologia mantém forte tensão com a agricultura denominada convencional ou produtivista (Abreu, Bellon, \& Torres, 2016). 
O atual momento é oportuno para aprofundar a compreensão de processos organizacionais e políticos que permitem mobilizar recursos e gerar incidência política na agroecologia. Avanços construídos em agroecologia e governança ambiental, em geral, estão sob constante ameaça. Um exemplo é a liberação de 290 novos agrotóxicos no mercado brasileiro, entre janeiro e julho de 2019 (Campanha Permanente Contra os Agrotóxicos e Pela Vida, 2019).

A constituição do campo da agroecologia, com suas interfaces com a política pública, podem ser compreendidas por meio da análise da atuação e trajetória de organizações não governamentais (ONGs), em relação a movimentos sociais e redes com as quais se articulam. A incidência política desses atores a partir de sua capacidade de mobilizar recursos para uma causa é tema presente na literatura e na reflexão sobre a dinâmica organizacional.

A incidência política, aqui entendida como capacidade de influência sobre cursos de ação pública, é estudada, de modo direto ou indireto, em diferentes disciplinas e abordagens teóricas. Destacam-se aqui as vertentes de estudos sobre movimentos sociais, em particular sob os enfoques da Teoria do Processo Político (TPP), da Teoria de Redes de Movimento Social (TRMS) e da Advocacy (Gohn, 1997). Para além de aspectos políticos e econômicos abordados por essas teorias, a captação ou mobilização de recursos por ONGs (ou organizações da sociedade civil, OSCs) está presente em publicações, cursos e eventos promovidos pela academia e por organizações de apoio (Armani, 2008; Andion, 2015; Estraviz, 2011).
Nesta pesquisa, mobilização de recursos contempla a obtenção de apoio tanto financeiro como político para o trabalho de promoção dos direitos e do exercício da cidadania (Santos, 2005, Armani, 2008; Andion, 2015). Ao analisar os recursos, consideram-se tanto os monetários como os não monetários (Santos, 2005; França Filho, \& Laville, 2004).

No Brasil, a agroecologia constitui-se como um contramovimento, uma via alternativa à política de modernização agrícola. Esta última provocou uma reação de grupos de agricultores familiares, não contemplados por subsídios e apoio governamentais, mas assessorados por ONGs, com perspectivas críticas, visando à construção democrática $\mathrm{e}$ à transformação social (Brandenburg, 2002). Nesse cenário, nasce, em 1990, a ONG Centro de Estudos e Promoção da Agricultura de Grupo (Cepagro).

O Cepagro foi fundado por professores universitários, organizações de pequenos agricultores e técnicos da extensão rural oficial do Estado de Santa Catarina, com a finalidade de estudar e propor novas estratégias de desenvolvimento para o meio rural, com ênfase na agricultura familiar e no estímulo ao associativismo (Turnes \& Schimidt, 2016). O grau de organização da agricultura familiar era considerado baixo e havia poucos atores dedicados ao seu desenvolvimento. Em 2003, passou a atuar também no meio urbano, em iniciativas de agricultura relacionadas com a gestão comunitária de resíduos orgânicos e hortas comunitárias e com consumidores urbanos agroecológicos. No início dos anos 2000, a agroecologia tornou-se central na sua atuação, com a agricultura familiar sendo vista como sua protagonista. 
Atualmente, o Cepagro tem como missão a promoção da agroecologia de maneira articulada em rede em comunidades rurais e urbanas, garantindo a incidência política (Cepagro, 2017).

Em sua trajetória, a organização enfrentou desafios e buscou caminhos para mobilizar recursos necessários a sua atuação e sua sustentabilidade, bem como para fortalecer a causa defendida. A repercussão de seu trabalho pode ser vista por indicadores de legitimidade e efetividade conquistadas, por exemplo, na gestão de resíduos orgânicos e na diversificação em áreas cultivadas com tabaco.

No início da pesquisa, a visão de incidência política, na organização estudada, estava restrita à participação em espaços institucionais de controle social (Isunza \& Lavalle, 2018) e a estratégias de advocacy (Libardoni, 2000) sobre a agenda de políticas públicas, âmbitos focalizados também por abordagens teóricas que tratam de incidência, ou capacidade de influência sobre cursos de ação pública. A trajetória da organização na causa da agroecologia, entretanto, sinalizava a necessidade de ampliar a compreensão sobre a relação entre as estratégias de ação da organização e seus efeitos na visão sobre o que significa mobilizar recursos e incidir politicamente. Assim, ao longo do trabalho, no diálogo entre perspectivas teóricas e análise dos dados do caso, o significado de incidência política mostrou-se mais amplo, incluindo diversas iniciativas de interação e/ou pressão política com o Estado; articulações coordenadas com grupos de base, com outras organizações, agentes públicos e/ou a sociedade civil em geral; fomento da visibilidade à causa defendida no debate público, ampliando a participação dos segmentos excluídos nos processos de tomada de decisões, com vistas a influenciar políticas e pessoas, de maneira a promover uma nova visão de sociedade e de mundo. Foi tornando-se visível que ações cotidianas da organização, como assessoria técnica aos grupos de base, organização de eventos e produção de materiais de comunicação, acabam constituindo alicerce para a incidência política, pois geram oportunidade de construir relações, confiança, conhecimento e legitimidade, trazendo, inclusive, oportunidades políticas.

O problema de pesquisa situa-se, portanto, na conexão entre um desafio prático e um teórico. O desafio prático é o de mobilizar recursos para a organização e para a causa da agroecologia e incidir politicamente, o que pode ganhar novos contornos ao se ampliar a compreensão sobre elementos da trajetória da organização, sua atuação, suas relações e seus resultados. Ao mesmo tempo, ao explorar a complexidade de um caso, é possível gerar alguma contribuição para o debate teórico, nas interfaces entre referenciais que abordam mobilização de recursos e capacidade de incidência de movimentos sociais sobre políticas públicas.

A pesquisa tem como objetivo, portanto, analisar a relação entre incidência política e mobilização de recursos, com base no caso do Cepagro e sua atuação na defesa da agroecologia. Para tal propósito, identifica-se o significado de incidência política realizada pela organização e suas estratégias nesses processos. Para ilustrar a relação entre incidência política e mobilização de recursos, os exemplos de atuação na gestão de resíduos orgânicos e na diversificação em áreas culti- 
vadas com tabaco são detalhados. A pesquisa, de caráter descritivo e interpretativo, foi realizada entre 2017 e 2018. A abordagem do estudo de caso é qualitativa. A coleta de dados foi baseada em entrevistas semiestruturadas com membros e ex-membros da organização, análise de documentos e observação participante natural e não sistemática.

\section{MOBILIZAÇÃO DE RECURSOS E INCI- DÊNCIA POLÍTICA: ORGANIZAÇÃO, MO- VIMENTO SOCIAL E CAUSA DEFENDIDA}

A mobilização de recursos vai além da captação de recursos monetários por meio de projetos específicos, constituindo esforço permanente, planejado e sistemático de fortalecimento da sustentabilidade da organização, em articulação com educação cidadã e participação social (Armani, 2008). A sustentabilidade assume o sentido de capacidade para tornar duradouro o valor social do projeto político-institucional da organização. Esta perspectiva implica posicionamento político, diálogo com outros atores, execução de parcerias, busca de credibilidade e legitimidade, capacidade de transformação e desenvolvimento institucional (Santos, 2005).

O elemento central da mobilização de recursos, conforme Santos (2009), é a ação educativa dirigida aos setores da sociedade, buscando o reconhecimento do papel de cada ator no enfrentamento dos problemas sociais. Brito \& Melo (2007) entendem que a mobilização de recursos consiste em fortalecer as Organizações da Sociedade Civil (OSCs) por meio da construção de uma base social de apoio político e financeiro, buscando aumentar sua autonomia financeira e política e sua capacidade de realização.
A concepção de mobilização de recursos nesta pesquisa contempla, portanto, aspectos monetários, técnicos e políticos, como meio para alcançar a sobrevivência de OSCs e a possibilidade de contribuir para transformações sociais (Armani, 2008; Andion, 2015). Os recursos, por sua vez, são classificados, conforme apresentado por Santos (2005), de acordo com princípios de economia solidária (França Filho \& Laville, 2004), na qual a solidariedade é central e a economia não se reduz ao mercado.

Baseados nessas referências e na realidade estudada do Cepagro, com sua defesa da causa agroecológica, os recursos são aqui considerados como: monetários, ou seja, recursos financeiros obtidos pela organização a partir de projetos com empresas, governos, fundações, agências de cooperação internacional, além de prestação de serviços, como também doações em dinheiro de pessoas físicas e jurídicas; não monetários, tais como serviços e apoios técnicos realizados, gratuitamente, por indivíduos, empresas e organizações, além de doações de materiais e equipamentos, parcerias na disponibilização de materiais, equipamentos e espaço para realização de atividades e, enfim, apoio político à organização e às suas causas.

Para compreender o significado da incidência política realizada pelo Cepagro na agroecologia, partiu-se de três categorias de análise da TPP: oportunidades políticas, repertórios de ação e redes sociais.

A TPP foi concebida nos anos 1980 para compreender os movimentos sociais, a partir de debates e análises comparativas entre a Teoria de Redes de Movimento Social 
(TRMS), enquanto abordagem americana, e a Teoria dos Novos Movimentos Sociais (TNMS), sob uma abordagem europeia. A TPP difundiu-se na América, enfatizando o processo político das mobilizações e as bases culturais que as sustentam, em lugar da ênfase nas bases econômicas, focalizadas por abordagens norte-americanas entre as décadas de 1970 e 1980 (Gohn, 1997).

A TPP destaca o desenvolvimento do processo político, o grau de organização dos grupos demandatários, a influência da cultura e a interpretação das ações coletivas. As ideias, a linguagem, os símbolos e as práticas de resistência cultural são vistas como veículos de significados sociais que configuram ações coletivas. Os descontentamentos, os valores e as ideologias foram resgatados a partir de abordagem que enfatiza a identidade coletiva dos grupos e a interação cultural (Gohn, 1997).

Os principais autores dessa abordagem são Charles Tilly, Sidney Tarrow e Doug McAdam, cujas ênfases distintas remetem a novos conceitos (Gohn, 1997), contribuindo para mudanças e reconstituição da teoria à medida que movimentos sociais e sociedade se transformam.

A TPP focaliza a construção e a consolidação da ação coletiva relacionada a um ambiente externo de abertura democrática e oportunidades políticas, no qual os indivíduos são encorajados ou desestimulados a engajar-se em lutas políticas (MacAdam, Tarrow, \& Tilly, 2009). Essas oportunidades são criadas pelo Estado, gerando um ambiente favorável por meio de incentivos e oportunidades para mobilizar e difundir ações coletivas para os movimentos am- pliados (Gohn, 1997). As mudanças de oportunidades políticas são analisadas por Tarrow (2009) em cinco dimensões: abertura do acesso para novos atores; realinhamento político no interior do sistema; surgimento de aliados influentes; divisões emergentes no interior da elite e; declínio na repressão pelo Estado.

Alonso (2009) destaca que "a mobilização se baseia num conflito entre partes, uma delas momentaneamente ocupando o Estado, enquanto a outra fala em nome da sociedade" (p. 56). Para a ação coletiva consolidar-se, além das oportunidades políticas, é necessário que os desafiantes criem ou se apropriem de estruturas de mobilização preexistentes. Nesse caso, a atuação de ONGs e redes sociais nos processos de mobilização fornecem bases organizacionais para os movimentos (Gohn, 1997; Alonso, 2012).

MacAdam, Tarrow, \& Tilly (2009) definem confronto político como reinvindicações que as pessoas sem poder encaminham, de maneira coletiva, a pessoas poderosas, visando a superar condições de injustiça. $O$ confronto inicia-se por meio de demonstrações públicas, para evidenciar a validade das demandas do movimento e o comprometimento com a causa defendida (Silva, 2015).

O termo "confronto" não está vinculado necessariamente ao uso da violência e sim à reivindicação de reparação. $O$ uso ou não da violência estará vinculado às ações do movimento e da organização, o que conduz a outro conceito-chave da TPP, aquele de repertórios de confronto (Tilly, 1995). Trata-se de "um conjunto limitado de rotinas que são aprendidas, compartilhadas e postas em ação por meio de um processo relativamente 


\section{A RELAÇÃO ENTRE INCIDÊNCIA POLÍTICA E MOBILIZAÇÃO DE RECURSOS NA AGROECOLOGIA}

deliberado de escolha" (Alonso, 2012, p.26). Segundo Abers, Serafim, \& Tatagiba (2014), Tilly empregou o conceito de repertório para analisar as escolhas dos movimentos quanto a sua forma, não ao conteúdo da ação coletiva.

Embora a noção de repertório seja útil para compreender a ação dos movimentos sociais, Abers et all. (2014) apontam seus limites na realidade brasileira. $\mathrm{Na}$ abordagem de Tilly, a categoria protesto é componente central do repertório. Entretanto, o caso brasileiro desafia esta concepção pela contínua atuação dos movimentos no interior do Estado, com sua importante interação com agentes públicos. Essa atuação dentro do Estado pode dar-se por meio de arenas participativas ou assumindo posições na burocracia, transformando o próprio Estado em espaço de militância política. Ainda, “[...] no caso brasileiro, a própria criação de movimentos importantes resulta de alianças entre indivíduos dentro e fora do Estado, o que coloca em xeque a visão do Estado como contraponto do movimento" (Abers et all. 2014, p. 331).

A partir desta ótica, Abers et all. (2014) sugerem complementar a noção original de repertório de Tilly com o conceito de "repertório de interação" entre Estado e sociedade civil. Essa visão inclui formas de ação coletiva de base colaborativa, permitindo incorporar a diversidade de estratégias utilizadas por movimentos sociais brasileiros na relação com o Estado.

No mesmo sentido, ao discutir possíveis dilemas entre autonomia e cooptação de movimentos sociais pelo Estado, Gomes \& Alves (2017) destacam a relevância dos espaços institucionais para concretizar mudanças sociais almejadas. Embora haja riscos associados à cooptação formal e informal, como dispersão e esvaziamento das lutas sociais, a cooptação também pode representar certo grau de partiha de poder e se configurar como estratégia de atuação dos movimentos sociais para a promoção de mudança institucional.

Outro conceito considerado pela TPP é aquele de redes sociais. A concepção é de que uma população dispersa só se organiza para uma ação comum quando se mobiliza dentro de redes e entendimentos culturais compartilhados. Observa-se como as pessoas estão organizadas, que valores compartilham e como se estabelecem confiança e cooperação (Gohn, 1997).

Na visão de Carlos (2011), mesmo considerando as redes sociais nos estudos de movimentos sociais, a TPP aborda de maneira superficial sua atuação e os processos de construção de solidariedade e identidades entre seus participantes. Para cobrir essa lacuna, Carlos (2011) cita os estudos de movimentos sociais utilizando a análise de redes, que originou a TRMS, abordagem utilizada no Brasil por autores como Diani (2003), Scherer-Warren $(2006,2011)$ e Lavalle, Castello, \& Bichir (2007). Esses autores assumem como premissa que as relações sociais estabelecidas entre indivíduos, atores coletivos, associações e/ou organizações constituem elemento estruturante da vida social.

\section{PERCURSO METODOLÓGICO}

Esta seção apresenta a organização em estudo e sua relação com a agroecologia; os 
procedimentos metodológicos da pesquisa; e exemplos de articulação entre a organização, os recursos mobilizados e a incidência na gestão dos resíduos orgânicos e na diversificação em áreas cultivadas com tabaco.

\section{Cepagro e agroecologia}

Fundado em 1990, o Cepagro contava com uma Junta Administrativa composta por cinco organizações que atuavam com grupos de base ( $1^{\circ}$ grau) no Estado de Santa Catarina. A função da nova organização era a de articular esforços em torno da agricultura familiar no Estado, como organização de $2^{\circ}$ grau. Em 1999, houve uma reestruturação do Cepagro e a agroecologia foi incorporada ao seu projeto político, o que se tornaria eixo central de sua prática na década de 2000. A organização passou a atuar diretamente com grupos de base, tornando-se organização de $1^{\circ}$ grau, mantendo a articulação com diversas organizações e redes na temática. A agroecologia é compreendida pelo $\mathrm{Ce}$ pagro (2017) como ciência, movimento social, sistema produtivo e propósito de vida, abarcando relações de justiça social, preservação ambiental e economia solidária, integrando os meios rural e urbano. Tais relações se traduzem em práticas coletivas, educativas, culturais e políticas visando à promoção da saúde; segurança e soberania alimentar e nutricional; conservação da agrobiodiversidade; ao resgate e à valorização dos saberes das comunidades; ao respeito aos ciclos da natureza; e à incidência política.

Em 2018, a organização atuava em prol da agroecologia em cinco áreas: desenvolvimento rural sustentável; agricultura urba- na; gestão de resíduos orgânicos; educação agroecológica; e articulações de redes agroecológicas. Essa atuação ocorre nas seguintes frentes: apoio ao Núcleo Litoral Catarinense da Rede Ecovida de Agroecologia; execução de projetos para diversificação e transição para a agroecologia, em especial famílias produtoras de fumo; articulação de ações na gestão de resíduos orgânicos, com foco na compostagem; hortas em escolas como ferramentas pedagógicas; apoio a centros de saúde e centros de referência em assistência social para implantar hortas medicinais; conexão e troca de experiências entre produtores e consumidores agroecológicos; participação em conselhos e fóruns; organização e participação em eventos relacionados à agroecologia; sistematização de metodologias de trabalho; produção de materiais para divulgação e fortalecimento dos temas trabalhados e da causa defendida.

\section{Método}

O artigo apresenta uma análise sobre a relação entre incidência política do Cepagro e sua capacidade de mobilização de recursos. Com este propósito, são identificados o significado de incidência política para a organização e suas estratégias de ação. $O$ recorte temporal do estudo é de 2006 a 2018, considerado pela organização como um "novo" período, pois passa a atuar com grupos de base, tendo a agroecologia como eixo central de suas atividades. Há mudanças na equipe e são desenvolvidos dois projetos estruturantes, com organizações de cooperação internacional, a partir de 2006.

A abordagem é qualitativa. A estratégia de investigação é o estudo de caso intrínseco (Stake, 2008), no qual o interesse está na 


\section{A RELAÇÃO ENTRE INCIDÊNCIA POLÍTICA E MOBILIZAÇÃO DE RECURSOS NA AGROECOLOGIA}

compreensão da complexidade do caso em si, como um sistema específico, único e delimitado, por meio do qual se pode aprender, também, sobre o fenômeno mais amplo que tal caso expressa. Embora não haja o propósito de construção de teoria a partir do caso, há a possibilidade de contribuição para proposições teóricas (Stake, 2008).

Foram utilizadas como fontes e técnicas de coleta de dados a observação participante, entrevistas semiestruturadas com membros e ex-membros da equipe e documentos da organização. Estes últimos se referem a atas de reuniões, projetos encaminhados a financiadores, editais de projetos, planejamento estratégico participativo, regimento interno, estatuto e informações do website da organização.

As entrevistas tornam acessíveis apenas os relatos das práticas e não as próprias práticas, que podem ser acessadas por meio da observação (Flick, 2004). O uso de diferentes fontes, dados e técnicas, bem como a triangulação, no sentido de considerar diferentes maneiras pelas quais o fenômenos é visto (Stake, 2008), qualificou a coleta dos dados e a construção dos resultados da pesquisa. O caráter reflexivo de um estudo de caso, no qual o pesquisador se compromete a ponderar as impressões da observação, dos dados e seus significados contextualizados (Stake, 2008), foi essencial durante todo o processo e para seus resultados.

A observação participante assumiu a forma natural, quando o pesquisador pertence à comunidade ou ao grupo que investiga (Gil, 2011), uma vez que um dos pesquisadores integra a equipe da organização, atuando na gestão administrativa financeira desde
2014. Trata-se de uma observação não sistemática, pois não foram elaborados plano de observação e instrumento de registro específico, mas ocorreu como parte da postura do pesquisador, que passou a estar no ambiente de trabalho enquanto membro da equipe e enquanto pesquisador, direcionando o olhar para certos fatos e relacionando-os com o objetivo da pesquisa.

O roteiro das entrevistas contemplou dez perguntas, elaboradas com base nas categorias de análise da TPP - oportunidades políticas, repertórios de ação e redes sociais - e na abordagem de mobilização de recursos adotada. No curso da pesquisa, incluiu-se a categoria relação Cepagro-Estado. As entrevistas foram conduzidas com cinco membros e um ex-membro da organização, selecionados em função de seu conhecimento profundo da organização e de sua causa, além de atuação na coordenação colegiada. As entrevistas foram gravadas com autorização dos entrevistados e transcritas. Uma pré-análise das entrevistas ocorreu durante a transcrição, destacando-se pontos considerados relevantes. Em seguida, o conteúdo foi analisado de modo a identificar exemplos de atuação da organização que evidenciassem como se desenvolve a relação entre mobilização de recursos e incidência política.

Gestão de resíduos orgânicos e diversificação em áreas cultivadas com tabaco

Dois exemplos de atuação do Cepagro revelaram-se propícios para analisar a relação entre essa atuação e as oportunidades políticas, repertórios e redes sociais, permitindo mobilizar recursos e incidir em causas: gestão de resíduos orgânicos e diversificação 
em áreas cultivadas com tabaco.

Os resíduos orgânicos são matéria-prima para um insumo básico da agricultura agroecológica, o composto. O método de compostagem utilizado pelo Cepagro consiste na compostagem termofílica em leiras estáticas, com aeração passiva, visando a otimizar o processo de transformação da matéria orgânica em adubo natural. Atuando nessa temática, a organização busca a valorização da fração orgânica, a conscientização sobre o ciclo do alimento, a qualificação dos recicláveis secos e a redução do volume de rejeitos destinados ao aterro sanitário, gerando renda e promovendo o desenvolvimento local sustentável.

$\mathrm{Na}$ temática da diversificação em áreas cultivadas com tabaco, o trabalho iniciou a partir da adesão do governo brasileiro, em 2005, à Convenção-Quadro para o Controle do Tabaco (CQCT), da Organização Mundial da Saúde (OMS), que inclui o apoio a atividades alternativas economicamente viáveis à cultura do tabaco, além de promoção de saúde e cuidado com o meio ambiente. A partir de 2006, foram criados programas e iniciativas nesse sentido, envolvendo órgãos de governo federal, estadual e municipal, ONGs e outras organizações. O Cepagro executou seu primeiro projeto com agricultores produtores de tabaco em 2007 , voltado à diversificação e transição produtiva para a agroecologia. Desde então, desenvolve projetos em vários municípios, com diversos parceiros.

\section{RESULTADOS}

Os resultados da análise são apresentados em três tópicos: significado de incidência política realizada pelo Cepagro e suas estratégias de ação; exemplos de oportunidades políticas e a relação entre Cepagro e Estado e; relação entre incidência política e mobilização de recursos para a organização e para a causa defendida.

Significado de incidência política e suas estratégias

A partir da análise das entrevistas, da observação e de informações documentais, considerando a literatura do campo, verifica-se que a incidência política realizada pelo $\mathrm{Ce}$ pagro se aproxima do conceito de advocacy (Libardoni,2000). Este último pode ser associado, nesse caso, com as seguintes iniciativas: interação e/ou pressão política com o Estado; articulações coordenadas com grupos de base, com outras organizações, agentes públicos e/ou a sociedade civil em geral; fomento da visibilidade à causa defendida no debate público, ampliando a participação dos segmentos excluídos nos processos de tomada de decisões, com vistas a influenciar políticas e pessoas, de maneira a promover uma nova visão de sociedade e de mundo.

Foram mapeadas cinco estratégias utilizadas pelo Cepagro. A primeira delas é a atuação em espaços de construção e controle social de políticas públicas, como conselhos, fóruns e audiências públicas. A participação em conselhos é uma estratégia de ação dos movimentos para relacionar-se com o Estado, denominada participação institucionalizada (Abers et all (2014). Além da incidência no conteúdo das políticas e do controle de sua implementação (Isunza \& Lavalle, 2018), esses espaços são considerados estratégicos para firmar parcerias e divulgar ações desenvolvidas pela organização. 


\section{A RELAÇÃO ENTRE INCIDÊNCIA POLÍTICA E MOBILIZAÇÃO DE RECURSOS NA AGROECOLOGIA}

A segunda estratégia é a sistematização de metodologias de trabalho e a produção de materiais, como cartilhas, folders, boletins técnicos, vídeos e livros. Essa estratégia possibilita estabelecer uma relação entre a prática dos sujeitos e as teorias, contribuindo para transformações individuais e coletivas.

A sistematização, nesta perspectiva, significa a construção da memória de uma experiência de desenvolvimento local, seguida pela divulgação de saberes relacionados às práticas, com vistas a estimular o intercâmbio e a confrontação de ideias, bem como contribuir na reconstituição de visões integradas dos processos de intervenção social (Santos, 2005, p. 112).

A terceira estratégia mapeada foi a participação em eventos, organizados muitas vezes pelo próprio Cepagro. Os eventos são considerados como oportunidades de diálogo entre membros dos grupos de base, ONGs e representações governamentais, troca de saberes, fortalecimento da causa e da identidade dos grupos. Diferentemente de espaços mais institucionalizados, como os conselhos, nos eventos há mais liberdade para ampliar o diálogo, estreitar relações e conhecer realidades locais, pois alguns acontecem na propriedade do agricultor, na agroindústria de uma cooperativa ou em comunidade da periferia.

A quarta estratégia, conduzida pela equipe de comunicação, compreende a divulgação das ações do Cepagro e de organizações parceiras relativas à agroecologia. A comunicação é um canal de mobilização para a causa, cuja efetivação é entendida pela equipe do Cepagro como um ato político.

As ações de comunicação devem servir à projeção da organização no espaço público como um interlocutor conhecido e reconhecido, capaz tanto de influenciar visões e opiniões no debate público como de mobilizar solidariedade, engajamento e contribuição material e financeira para causas sociais. [...] O fundamental e verdadeiro ato político da comunicação é fazer com que a sociedade em geral acredite e, consequentemente, apoie a luta cidadã (Armani, 2008, p. 50).

A quinta estratégia mapeada é o trabalho em rede com parceiros, central nas ações do Cepagro, desde sua origem. Atualmente, exemplos de redes das quais o Cepagro participa e articula são a Rede Ecovida de Agroecologia e a Rede Semear Floripa de Agricultura Urbana. $\mathrm{O}$ trabalho em rede é entendido pela equipe como ações desenvolvidas em parceria com pessoas e/ou organizações que aportam qualidades e capacidades em torno de um objetivo comum. Com efeito, as redes sociais

[...] referem-se às comunidades de sentido construídas histórica ou voluntariamente em torno de afinidades/identificações ou objetivos comuns relacionados a uma causa, que serão os fios da rede. Por sua vez, esses fios são conectados entre si através dos elos da rede, que são os indivíduos e/ou organizações participantes dessa relação sociocomunitária (Scherer-Warren, 2011, p. 65-66).

Segundo Scherer-Warren (2011), os valores compartilhados são os fios que ligam os elos da rede e estes últimos são os indivíduos e 
as organizações que a integram. Para o Cepagro, os fios da rede seriam a confiança, a cooperação, a solidariedade, a igualdade, a justiça e a transformação social. A causa defendida e o senso de pertencimento à rede constituem elemento de identidade vistos como compartilhados entre seus integrantes.

Oportunidades políticas e a relação entre Cepagro e Estado

A incidência política do Cepagro é influenciada por variados fatores, entre eles as oportunidades políticas e a maneira como a organização busca se relacionar com o Estado.

No que se refere a esse ponto, a eleição do vereador Marcos José de Abreu (Marquito) é reveladora. Marquito atuou no Cepagro entre 2002 e 2016, tendo sido o segundo vereador mais votado em Florianópolis nas eleições em 2016, recebendo 5.448 votos. Sua agenda política inclui a defesa da agroecologia e da agricultura urbana, além da promoção da gestão de resíduos orgânicos, da compostagem e da segurança alimentar e nutricional. Essa eleição contribuiu para evidenciar a incidência e a legitimidade de causas defendidas pelo Cepagro e para fortalecer a temática da agroecologia no município. Sua presença na estrutura estatal sensibiliza pares, envolvendo novos atores nos temas mencionados. Como exemplo, destaca-se a articulação iniciada pelo gabinete do vereador para a estruturação de uma rede de compostagem em Florianópolis, a partir da qual diferentes atores foram estimulados a contribuir.

Durante o 2. Encontro Municipal de Agricul- tura Urbana, em 2016, organizado pela Rede Semear Floripa, com apoio do Cepagro, foram realizadas atividades que culminaram no mapeamento de demandas para a agricultura urbana no município e elaboração de uma carta. Essa carta foi apresentada a candidatos do Legislativo e do Executivo, que assinaram compromisso com as demandas, caso eleitos.

Ainda como resultado do encontro, constituiu-se um grupo de trabalho composto por representantes da sociedade civil e servidores públicos para elaboração de minuta de decreto para instituir um programa municipal de agricultura urbana. Como fruto de articulação política e trabalho técnico de representantes da sociedade civil e servidores do Executivo e do Legislativo municipais, esse Decreto ( $n$ - 17.688), assinado pelo prefeito em 2017, instituiu o Programa Municipal de Agricultura Urbana em Florianópolis. Com base na minuta desse decreto e na Política Nacional de Agricultura Urbana, o vereador Marquito elaborou o PL 17002/2017 para instituir a PMAPO. Esse PL foi aprovado em 06 de junho de 2018, com apenas um voto contrário, ainda que o vereador proponente integre a pequena bancada da oposição na Câmara. Tanto o Decreto ํo 17.688 como o PL no 17.002 fortalecem a gestão dos resíduos orgânicos e a compostagem, incentivando o reaproveitamento eficiente e sustentável de recursos e insumos locais.

A análise dos dados pesquisados evidencia que a organização se coloca como parceira na relação com o Estado, buscando "somar", "agregar", "dialogar", construir", verbos esses utilizados pelos entrevistados: 


\section{A RELAÇÃo ENTRE INCIDÊNCIA POLÍTICA E MOBILIZAÇÃO DE RECURSOS NA AGROECOLOGIA}

base sólida de argumentação, porque tem entendimento do que está falando. Mas nunca é no tom do clássico enfrentamento, perfil destrutivo, que destrói para vir com o novo. [...] O Cepagro é mais o perfil reformista, aceita a estrutura que está posta, que não é ideal e vamos reformando. Nessa perspectiva de uma organização que é reformista, adotamos o perfil de construção com o Estado. Isto está totalmente claro para mim; somos mais de construção do que conflito e embate (Entrevista com diretor-presidente do Cepagro, que atua há dez anos na organização).

Essa relação de diálogo e construção com o Estado ocorre sobretudo em espaços como conselhos, fóruns, eventos e redes. Convém também realçar os termos de cooperação técnica firmados com entes públicos. $\mathrm{O} \mathrm{Ce}$ pagro mantém uma atuação com caráter construtivo, propositivo e dialógico, mesmo quando são necessários enfrentamentos. $\mathrm{O}$ caráter apartidário da organização também foi destacado, o que facilitaria o diálogo com variados governos e instâncias. Essa postura amplia o repertório de interação (Abers et all., 2014).

A relação entre incidência política e mobilização de recursos

A mobilização de recursos, conforme explicitado anteriormente, é considerada como processo de fortalecimento organizacional, fundamentado na construção de uma base social de apoio político e financeiro. Trata-se de um processo pelo qual uma organização promove educação cidadã, participação social e mobilização de recursos, monetários e não monetários, para a própria organização e para a causa, visando a contribuir para a transformação social.

Desta maneira, a incidência política é parte do processo de mobilização de recursos do Cepagro, que o legitima e fortalece. Com efeito, a mobilização de recursos qualifica e potencializa a incidência política realizada pela organização. Esta incidência é baseada na articulação e mobilização de grupos de base, de outras organizações, de agentes públicos e da sociedade civil em geral, em torno da causa da agroecologia, não se restringindo a uma relação de pressão ou interação política entre a organização e o Estado. Segundo os entrevistados, a incidência política expande-se no processo de mobilização da sociedade civil, que colabora com a construção de uma base social para a organização, conferindo legitimidade, credibilidade e relevância social para a agroecologia com diferentes atores.

Na Figura 1, procura-se ilustrar essas relações, considerando a complexidade e a multidimensionalidade entre os fenômenos da incidência política e da mobilização de recursos, apontando igualmente as estratégias para tal. 
Figura 1. Relação entre incidência política e mobilização de recursos

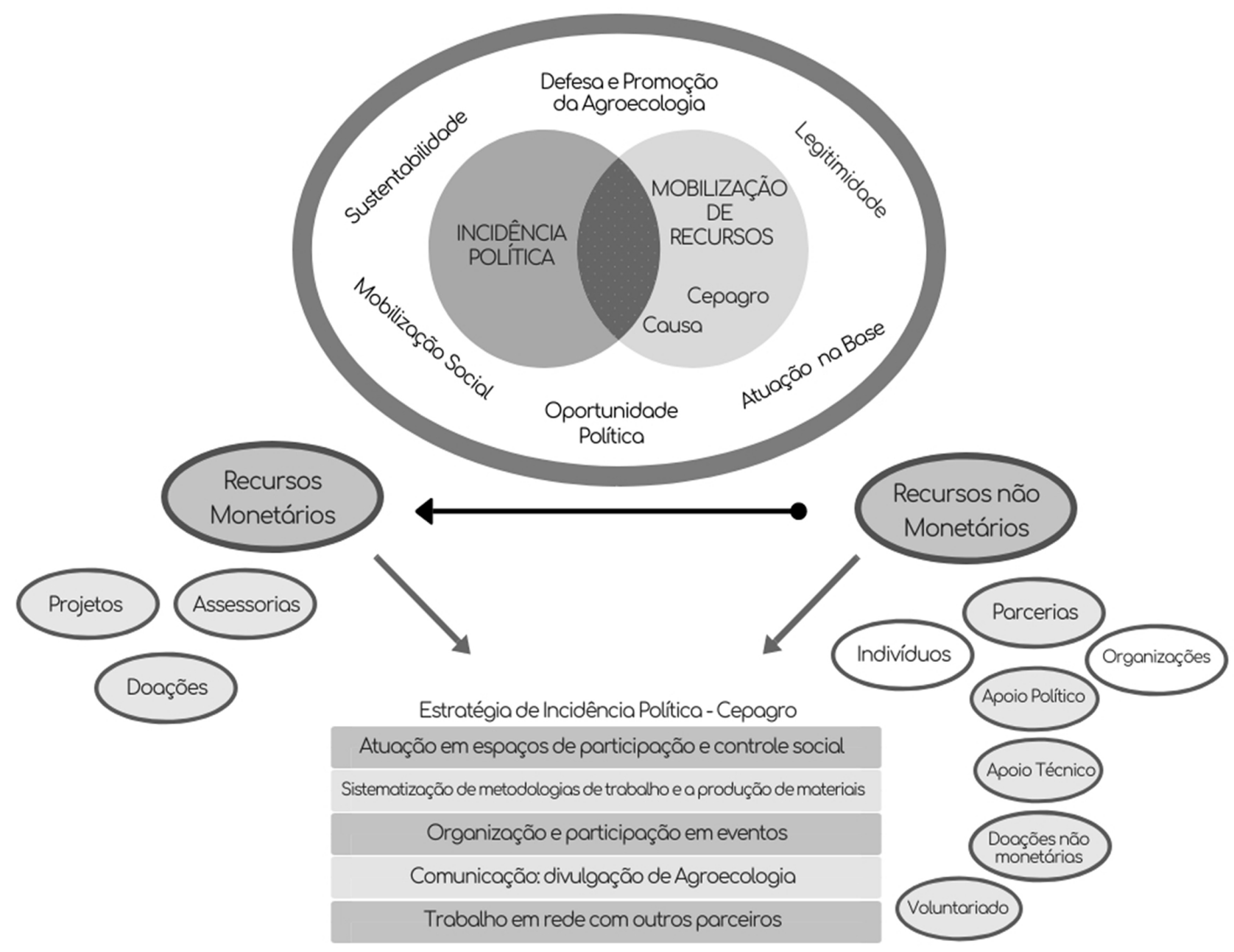

As estratégias de incidência política da organização são viabilizadas a partir de recursos, monetários e não monetários, mobilizados especialmente por meio de projetos com financiadores, assessorias técnicas e trabalho voluntário. Um exemplo da estratégia da organização de eventos foi o Festival Santa Catarina Agroecológico, em 2017, com o objetivo de promover e valorizar a agroecologia, com destaque para o papel da mulher. Foram mobilizados recursos monetários, via patrocínio da Fundação Banco do Brasil (FBB), para custeio de transporte e hospedagem de participantes, aquisição de alimentos e produção de material de di- vulgação. Recursos não monetários foram mobilizados na forma de trabalho voluntário para recepção e cadastramento dos participantes, cobertura de comunicação e uso gratuito do auditório da Empresa de Pesquisa Agropecuária e Extensão Rural de Santa Catarina, Epagri.

A Figura 1 evidencia que incidência política e mobilização de recursos se inter-relacionam em um macroambiente de promoção da causa, de atuação com grupos de base e ações de participação social para a temática, conferindo legitimidade para a organização e para a causa defendida. 
Focalizando a atuação com grupos de base, a análise das estratégias de incidência política, as oportunidades políticas e a mobilização de recursos para a organização e para a causa, foi possível elaborar as Figuras 2 e 3 , contemplando linhas do tempo da atuação do Cepagro na gestão de resíduos orgânicos e na diversificação em áreas cultivadas com tabaco.

A representação em uma linha do tempo não significa que se trate de um processo linear. Os elementos inter-relacionam-se e influenciam-se ao longo do tempo. Os itens em azul referem-se a ações desenvolvidas com grupos de base, com apoio de recursos monetários mobilizados a partir de projetos nos quais a organização foi proponente e/ou parceira. Em preto, são elencadas as estratégias de incidência política. Em vermelho, são destacadas as oportunidades políticas mapeadas no período.

A linha do tempo relativa à gestão de resíduos orgânicos (Figura 2) inicia em 2003, com ações em grupos de base, como o Programa Vivendas, que contemplava a reciclagem de materiais e resíduos orgânicos, e finaliza em 2018, com o lançamento do Edital do Fundo Nacional do Meio Ambiente (FNMA) e do Fundo Socioambiental Caixa (FSA) o 1/2017, que selecionou 11 instituições, incluindo a Prefeitura de Florianópolis, que recebeu cerca de $\mathrm{R} \$ 1$ milhão para executar ações de compostagem no município. Entendido como uma oportunidade política, o referido edital foi lançado para apoio a projetos de compostagem no valor de $\mathrm{R} \$ 10$ milhões. O objetivo foi a seleção de projetos integrados de separação na fonte e reciclagem da fração orgânica de resíduos sólidos em municípios ou consórcios públicos intermunicipais que atuem na gestão de resíduos sólidos.

No ano de 2008, inicia-se o projeto Revolução dos Baldinhos, a partir de um surto de leptospirose na comunidade Chico Mendes. A solução foi encontrar um destino adequado para os resíduos orgânicos, pois com a ineficiente coleta, ficavam espalhados pelas ruas. Com apoio do Cepagro, organizações locais e moradores, iniciou-se o projeto para realizar a gestão dos resíduos orgânicos, por meio da separação dos resíduos pelos moradores, destinação em pontos de entrega voluntária e coleta por agentes comunitários do projeto para compostagem. Esse trabalho gerou aprendizagem e permitiu sistematizar sua metodologia, premiada como Tecnologia Social pela FBB, tendo sido replicada em outros locais do país.

O Cepagro realizou, ainda, assessorias técnicas para organizações como o SESC/SC e a subprefeitura da Lapa, em São Paulo, responsável por importante pátio de compostagem. Além de elaborar o projeto técnico, assessorou a implantação e o monitoramento de operações, o que permitiu aprimoramento técnico e geração de referências para operacionalizar pátios de compostagem de maior porte.

Ainda como estratégia de incidência política, o Cepagro produziu materiais técnicos, como o Boletim Técnico de Compostagem para Pátios de Pequeno Porte e o manual "Compostagem doméstica, comunitária e institucional de resíduos orgânicos: manual de orientação". Este último foi elaborado em cooperação com o SESC/SC e o Ministério do Meio Ambiente. 
A organização realizou eventos e cursos, tais como o Gestão Comunitária de Resíduos Orgânicos e Agricultura Urbana, promovido anualmente desde 2015. Trata-se de um meio para contribuir com a formação de lideranças comunitárias, agentes públicos e outras pessoas interessadas.

Paralelamente, a organização participou de grupo de trabalho de compostagem no Conselho Nacional do Meio Ambiente (CONAMA), em 2016. O grupo dedicou-se a elaborar uma resolução estabelecendo critérios e procedimentos para garantir a qualidade do composto e sua utilização segura, além de orientar os procedimentos de licenciamento ambiental das unidades de compostagem de resíduos sólidos orgânicos, visando a be- nefícios à agricultura, à saúde pública e ao meio ambiente (CONAMA, 2017).

Essas ações contribuíram para ampliar a visibilidade da temática, para qualificar discussões e ações técnicas, gerar diálogo entre diferentes atores e organizações e mobilizar pessoas para a causa. Como evidência, no edital FNMA/FSA no $1 / 2017$, entre os quatro materiais disponibilizados como referências técnicas, três se relacionam a ações do Cepagro: o manual de operação supracitado, o projeto Revolução dos Baldinhos e o projeto de compostagem da subprefeitura paulistana. Conclui-se que as ações do Cepagro com grupos de base e realizando ações de incidência política (Figura 2), somadas a outras oportunidades políticas do período, contribuíram para o lançamento do edital.

Figura 2. Linha do tempo da atuação do Cepagro na gestão de resíduos orgânicos

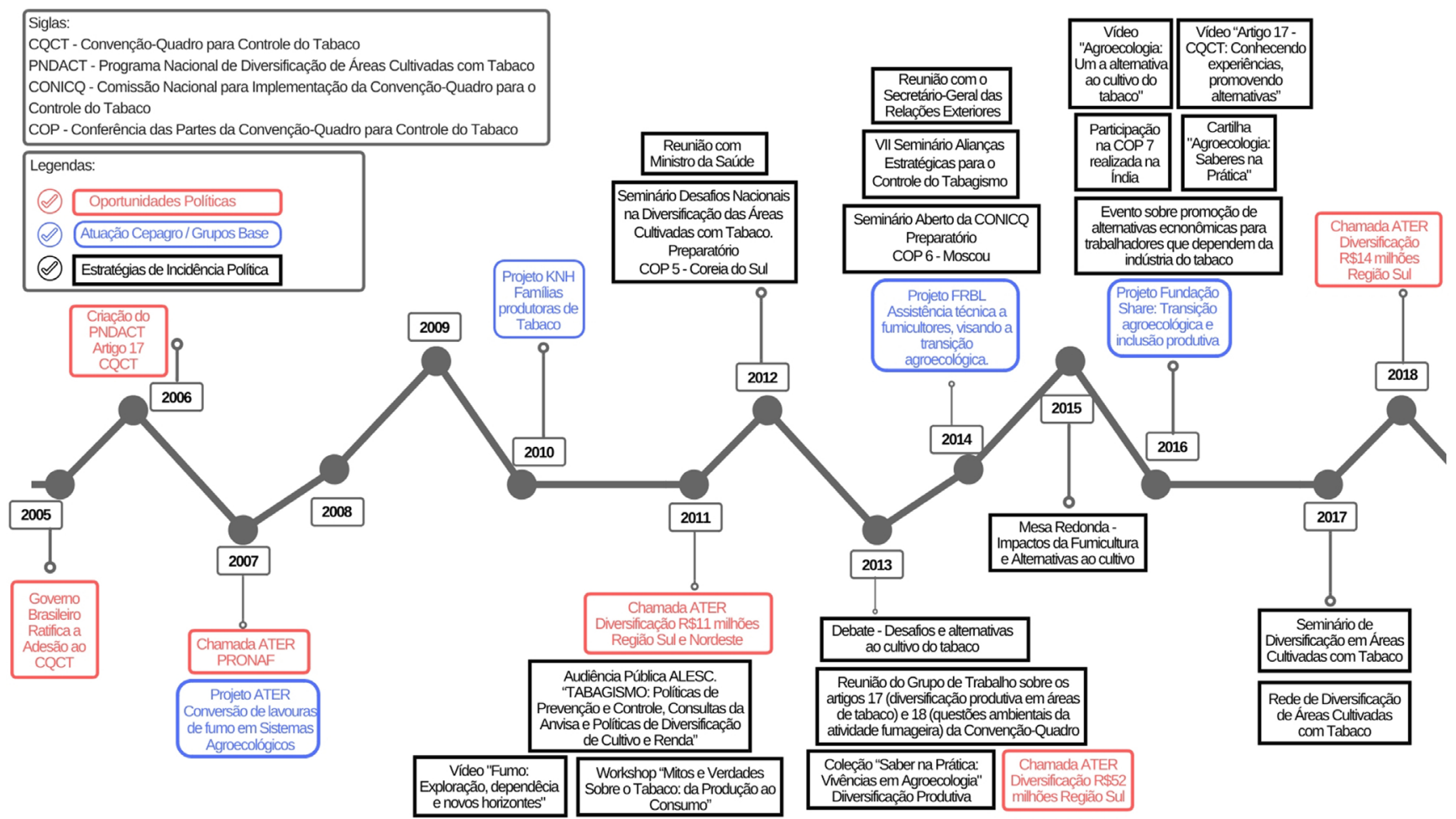




\section{A RELAÇÃo ENTRE INCIDÊNCIA POLÍTICA E MOBILIZAÇÃO DE RECURSOS NA AGROECOLOGIA}

Figura 3. Linha do tempo da atuação do Cepagro na gestão de diversificação em áreas cultivadas com tabaco

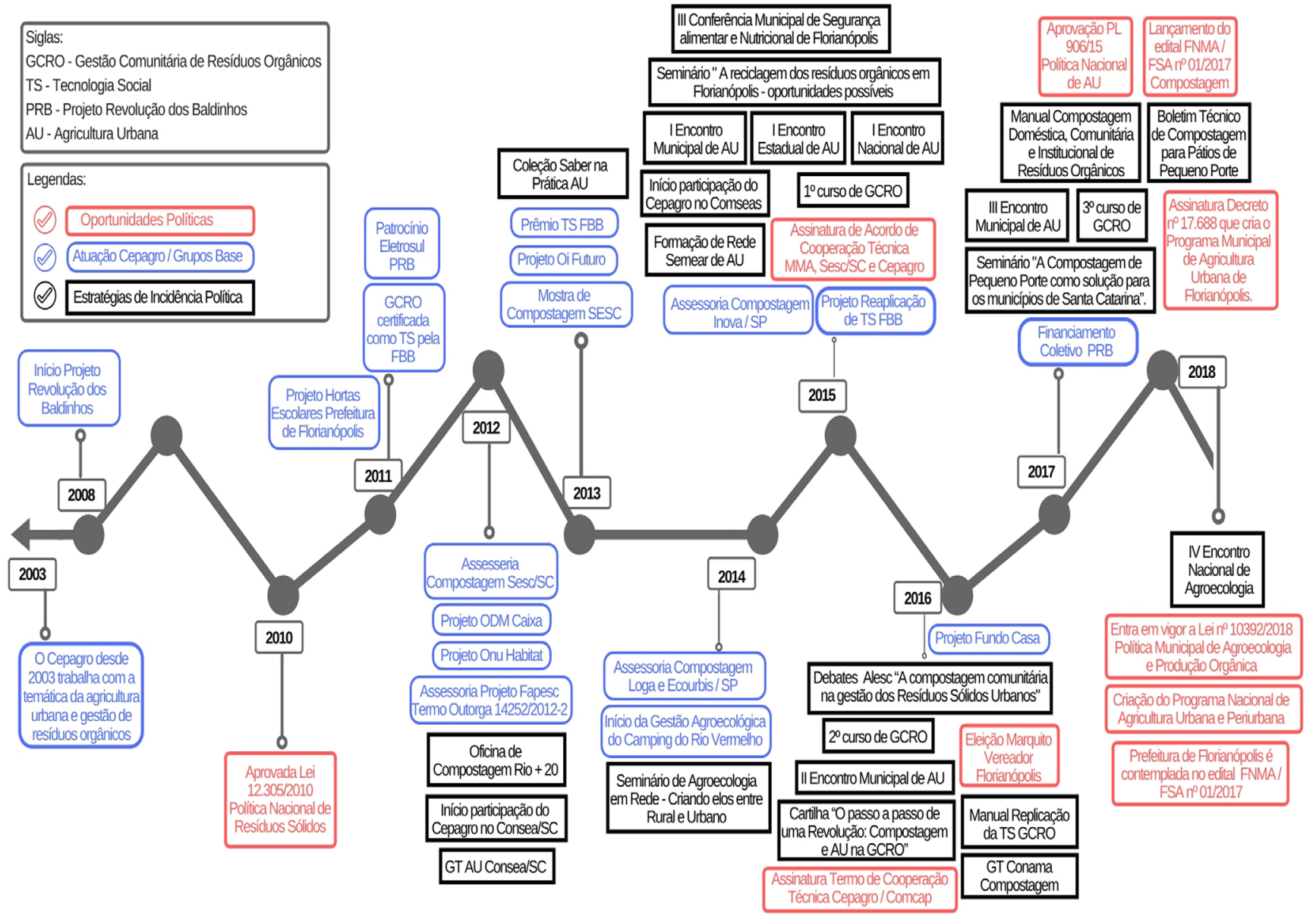

Na temática da diversificação em áreas cultivadas com tabaco (Figura 3), a linha do tempo inicia em 2005, com a oportunidade política da ratificação, pelo governo brasileiro, da adesão à convenção da OMS relativa ao controle do tabaco (CQCT/OMS). A linha segue até 2018, quando o governo lança a Chamada Pública $n^{\circ}$ 04/2018, no valor de $R$ \$ 14.237.928,91, para assistência técnica e extensão rural (ATER), que beneficiará 3.840 Unidades Familiares de Produção Agrária (UFPAs).

A CQCT trata, nos artigos 17 e 18, do apoio às atividades alternativas economicamente viáveis à cultura do tabaco e a proteção ao meio ambiente e saúde das pessoas, respectivamente. A Secretaria Especial de Agricultura Familiar e do Desenvolvimento Agrário (SEAD) é a responsável pela implementação do artigo 17, por meio do Programa Nacional de Diversificação em Áreas Cultivadas com Tabaco (PNDACT), criado em 2006 para gerar alternativas de renda aos agricultores e evitar que aqueles que têm na fumicultura sua principal atividade diminuam sua renda, em função da desejada redução mundial do consumo de tabaco. O Cepagro executou seu primeiro projeto com agricultores produtores de tabaco em 2007, por meio de chamada de ATER/Pronaf, desvinculado do PNDACT, mas com 
público mapeado pela organização como prioritário para diversificação e transição produtiva para a agroecologia. Desde então, desenvolve projetos na temática. Um desses projetos foi realizado em 2014 e 2015, em parceira com o Ministério Público de Santa Catarina, com recursos do Fundo para Reconstituição de Bens Lesados (FRBL), visando à transição agroecológica para fumicultores em cem propriedades do Alto Vale do Rio Tijucas.

O Cepagro produziu materiais relacionados à temática, alguns deles em parceria com o Ministério do Desenvolvimento Agrário e com o INCA. De outra parte, a organização participou e organizou eventos, colaborando, em 2017, com a organização do seminário "Diversificação em áreas cultivadas com tabaco." O evento recebeu mais de 30 ONGs, coooperativas e agências governamentais, que debateram potencialidades, desafios e estratégias de diversificação em áreas cultivadas com tabaco, visando a atender as recomendações dos artigos 17 e 18 da CQCT e aperfeiçoar o PNDACT. O encontro contribuiu para o desenho da chamada supracitada (ATER/PNDACT), lançada em 2018, abrangendo 42 municípios produtores de tabaco do Rio Grande do Sul e Santa Catarina, não incluído o território de atuação do Cepagro.

\section{CONCLUSÕES}

A pesquisa evidencia que os resultados da incidência política são verificados no longo prazo. Na temática da gestão de resíduos orgânicos, o Cepagro iniciou suas ações em 2003, quando realizou uma série de ações com grupos de base e ações de incidência no âmbito institucional. Somente a partir de
2015, no município em que está sediado, a temática em questão alcançou evidência pública: as ações foram intensificadas e ampliaram-se as oportunidades políticas. Considerando a diversificação em áreas cultivadas com tabaco, além do longo prazo, evidencia-se que a incidência do trabalho da organização gera efeitos em outros territórios. Não diretamente para a organização, mas sim para a causa.

Na relação entre ONG e Estado, no período analisado, predominou a postura de colaboração e construção em prol das causas defendidas pela organização. Esta colaboração é evidenciada pelas parcerias com entes públicos na elaboração de materiais técnicos, na organização conjunta de eventos e em termos de cooperação técnica firmados. Tal ambiente colaborativo pode alterar-se, tornando-se mais conflituoso, com mudanças de contexto político e de lideranças no governo. De todo modo, conclui-se que, além do Estado como gerador de oportunidades políticas, as ONGs e a sociedade civil são polos de força e dinamismo capazes de influenciar processos de abertura de oportunidades políticas. Por meio do trabalho de incidência política, criando referências, apresentando demandas da base, sensibilizando a sociedade, servidores públicos e outros agentes no governo, as ONGs podem influenciar esse processo.

Quanto aos recursos, monetários e não monetários, a organização estudada mobiliza-os via parcerias com organizações internacionais, editais públicos e privados e prestação de serviços, entre outros. Essa mobilização de recursos permite que as estratégias de incidência política sejam realizadas no sentido de envolvimento social, sistematização 
de experiências e metodologias, com o desenvolvimento de referências técnicas. Estas ações contribuem para a ampliação da visibilidade da temática e para a promoção, defesa, legitimidade e o fortalecimento da causa agroecológica.

Desta maneira, evidencia-se que, ao mobilizar recursos para as ONGs, recursos são destinados para a causa. Além disso, uma causa legítima e fortalecida colabora para que organizações tenham projetos aprovados, da mesma forma que colabora para que sejam lançados editais contemplando essas temáticas. As ações de incidência política de uma organização, em alguns casos, geram oferta de recursos que a mesma não acessa necessariamente, mas outras organizações próximas podem acessar. Assim, as ações podem seguir e a visibilidade da causa se amplia.

Entre as limitações da pesquisa, está a incipiente articulação entre abordagens teóricas que poderiam ser utilizadas para a compreensão do fenômeno. Uma das possibilidades é considerar teorias associadas ao conceito de campo (Bourdieu, 2003; 2011), para analisar o compartilhamento de recursos por diversas organizações para uma mesma causa. É possível avançar, também, no diálogo com trabalhos que discutem oportunidades e riscos de cooptação em processos de institucionalização de políticas públicas, a exemplo de Gomes \& Alves (2017).

\section{REFERÊNCIAS}

Abers, R., Serafim, L., \& Tatagiba, L. (2014). Repertórios de interação estado-sociedade em um estado heterogêneo: A experiência na era Lula. Dados, (57)325-357. https://doi. org/10.1590/0011-5258201411

Alonso, A. (2009). As teorias dos movimentos sociais: Um balanço do debate. Lua Nova, (76)49-86. https://doi.org/10.1590/ S0102-64452009000100003

Alonso, A. (2012). Repertório, segundo Charles Tilly: História de um conceito. Sociologia \& Antropologia, 2(3)21-41. https:// doi.org/10.1590/2238-38752012v232

Andion, C. (2015). Investimento social privado e mobilização de recursos na grande Florianópolis. Florianópolis: UDESC.

Armani, D. (2008). Mobilizar para transformar: A mobilização de recursos nas organizações da sociedade civil. São Paulo: Peirópolis.

Brito, M., \& Melo, M. E. (2007). Hábitos de doar e captar recursos no Brasil. São Paulo: Peirópolis.

Bourdieu, P. (2003). Questões de sociologia. Lisboa: Fim de Século.

Bourdieu, P. (2011). Razões práticas: Sobre a teoria da ação. Campinas: Papirus.

Brandenburg, A. (2002). Movimento agroecológico: Trajetória, contradições e perspectivas. Caminhos da agricultura. ANPPAS.

Campanha Permanente Contra os Agrotóxicos e pela Vida. 22 julho 2019. Quintal de agrotóxicos: governo libera mais 51 venenos. Disponível em https://contraosagrotoxicos.org/quintal-de-agrotoxicos-governo-libera-mais-51-venenos/. 
Carlos, E. (2011). Contribuições da análise de redes sociais às teorias de movimentos sociais. Sociologia Política, 19(39)153$166 . \quad \quad h t t p s: / / d o i . o r g / 10.1590 / S 0104-$ 44782011000200011

Centro de Estudos e Promoção da Agricultura de Grupo, Cepagro (2017). Relatório planejamento estratégico participativo. Florianópolis: Cepagro.

Conselho Nacional do Meio Ambiente (2017). Proposta de resolução Conama que define critérios para produção de composto de resíduos sólidos orgânicos: relatório das reuniões do GT Compostagem. Disponível em <http://www2.mma.gov.br/port/conama/ processos/8BF1C37E/Relatorio_GTCompostagem.pdf>.

Diani, M. (2003). Networks and social movements: A research program. In M. Diani, \& D. MacAdam (eds). Social movements and networks: Relational approaches to collective Action. Oxford: Oxford University.

Estraviz, M. (2011). Um dia de captador. São Paulo: Zeppelini.

Flick, U. (2004). Uma introdução a pesquisa qualitativa. 2. ed. Porto Alegre: Bookman.

França Filho, G. C., \& Laville, J. (2004). Economia solidária: Uma abordagem internacional. Porto Alegre: UFRGS.

Gil, A. C. (2011). Métodos e técnicas de pesquisa social. 6. ed. São Paulo: Atlas.

Gohn, M. G. (1997). Teoria dos movimentos sociais: Paradigmas clássicos e contemporâneos. São Paulo: Edições Loyola.
Gomes, M.V.P., \& Alves, M.A. (2017). Como se cria um Ministério? O processo de cooptação como mecanismo de distensão na relação entre movimentos sociais e Estado. Revista de Administração Pública, 51(3)388-406. https://doi.org/10.1590/0034-7612154913

Isunza Vera, E.; Lavalle, A. G. (2018). Controles democráticos no electorales y reg ímenes de rendición de cuentas en el Sur global: México, Colombia, Brasil, China y Sudáfrica. Bern: Peter Lang.

Lavalle, A. G., Castello, G., \& Bichir, R. (2007). Protagonistas na sociedade civil: Redes e centralidades de organizações civis em São Paulo. Dados, 50(3)465-498. https:// doi.org/10.1590/S0011-52582007000300002

Libardoni, M. (2000). Fundamentos teóricos e visão estratégica da advocacy. Estudos Feministas, 8(2)191-206. https://doi. org $/ 10.1590 / \% 25 x$

McAdam, D., Tarrow, S., \& Tilly, C. (2009). Para mapear o confronto político. Lua Nova, (76)11-48. https://doi.org/10.1590/S010264452009000100002

Santos, T. C. S. S. (2005). As diferentes dimensões de sustentabilidade em uma organização da sociedade civil brasileira: o caso da Gapa-Bahia. (Dissertação de Mestrado). Universidade Federal da Bahia, Escola de Administração.

Santos, T. C. S. S. (2009). Organizações da sociedade civil e as contribuições teóricas contemporâneas acerca da sustentabilidade. Cadernos Gestão Social, 2(1)105-120. 


\section{A RELAÇÃo ENTRE INCIDÊNCIA POLÍTICA E MOBILIZAÇÃO DE RECURSOS NA AGROECOLOGIA}

Scherer-Warren, I. (2006). Das mobilizações às redes de movimentos sociais. Sociedade e Estado, 21(1)109-130. https://doi. org/10.1590/S0102-69922006000100007

Scherer-Warren, I. (2011). Redes da sociedade civil: Advocacy e incidências possíveis. In C. Martinho, \& C. Félix. (eds). Vida em rede: Conexões, relacionamentos e caminhos para uma nova sociedade. Barueri, SP: Instituto C\&A.

Silva, A. C. M. (2015). Os bastidores da sociedade civil: Oportunidades políticas e estruturas de mobilização na construção de redes de defesa dos direitos humanos. (Tese de Doutorado). Universidade Federal de Sergipe, Pós-Graduação em Sociologia.

Stake, R. E. (2008). Case studies. In N. K. Denzin, \& Y. S. Lincoln. (Eds). Strategies of qualitative inquiry. 3rd ed. Thousand Oaks, CA: Sage Publications, p. 134-164.

Tarrow, S. (2009). Poder em movimento: Movimentos sociais e confronto político. Petrópolis, Vozes.

Tilly, C. (1995). Contentious repertoires in Great Britain. In T. MARK. (ed.). Repertoires and cycles of collective action. Durham: Duke University Press.

Turnes, V. A., \& Schimidt, V. D. B. (2016). A agroindustrialização nas encostas da Serra Geral e o papel do CEPAGRO. In W. SCHMIDT. (ed.). Agroecologia sem agricultores locais? Uma reflexão sobre implicações da agroindustrialização em projetos de desenvolvimento sustentável de territórios rurais. Florianópolis: NEA EduCampo/UFSC, p. 99121. 